\title{
Risk management in the financing of ICO projects: prospects for the use of modern technologies in Kazakhstan
}

\author{
Raigul Doszhan ${ }^{1,}$, , Gaukhar Alimbekova ${ }^{1}$, Zhanna Kalymbekova ${ }^{1}$, Meruyert Talasbek ${ }^{1}$ \\ ${ }^{1}$ Al-Farabi Kazakh National University, al-Farabi Ave. 71, 050040 Almaty, Kazakhstan
}

\begin{abstract}
The article discusses the potential risks when investing in projects and ICO. The initial coin offering (ICO) is a new way for startups to raise funds and for blockchain startups, perhaps the predominant way. This new method of fundraising has only been around for a couple of years and has already enabled entrepreneurs and innovators to raise billions of dollars from global investors. The relevance of the article is to determine the advantages in the financing of ICO projects and to determine their elimination by determining the main risks arising from the financing. Analyzing the financing on foreign experience, to determine the prospects of ICO projects implemented in Kazakhstan. The purpose of this article is to determine the factors affecting the development of the economy in the financing of ICO projects. The need to study the nature of risk management in the financing of ICO-projects will allow to understand in more detail the prospects for the use of modern technologies in Kazakhstan.
\end{abstract}

\section{Introduction}

Over the past decade, new types of financing have emerged. In the real economy, there are two main ways of financing - attracting own and borrowed funds [1]. In the digital age, financial investment is also carried out in the form of cryptocurrencies and tokens. At the same time, the main motivating factor for investors is the relevance, high competitiveness and profitability of the project. In the first decade of the 21 st century, the most dynamic economic drivers were venture capital funds and ICOS, which represent essentially original economically sound business proposals with high economic dividends and risks [2]. Both traditional and a number of alternative ways to attract financial resources can be implemented through the mechanism of the so-called initial token offering (ICO).

A wide range of issues related to the risks of companies and digital development, reflected in the works of Pukala, R., Sira, E., Vavrek, R., Ziyadin, S., Doszhan, R., Borodin, A., Omarova, A., Ilyas, A., Saparova, G., Ermekbaeva, B., Supugaliyeva, G., Zharaskyzy, G., Mukhtarova, K., Kupeshova, S. [3, 4, 5, 6, 7, 8].

Before we analyze the financing in ICO and determine the risks in financing, we provide the essence and the main concept of the ICO mechanism. Initial token offering

* Corresponding author: $\underline{\text { rdd2011@mail.ru }}$ 
(ICO) is a mechanism for raising capital by issuing new digital assets - tokens and selling them to investors [9]. Tokens differ in their functions - they allocate cryptocurrencies, tokens-shares and utility-tokens [10].

Depending on the tasks of the organizers ICO differ in the following types of tokens [11]:

- tokens-cryptocurrencies or coins in ICO digital currency. This category includes appcoins or application tokens, which are used as an internal virtual currency;

- tokens-shares that require payment of dividends to investors;

- credit tokens, according to which investors receive interest income.

One of the emerging and trending areas of support and financing of innovative and technological projects is the holding of the ICO on the basis of the principles of crowdfunding or crowdselling [12].

Crowdfunding is literally translated as joint public funding or collaboration, which is usually carried out through the Internet in the form of a contribution or donation to the implementation of projects. At the same time, the participants of crowdfunding, or donors, can count on the opportunity to use the results of the project implemented with the collected funds in the future [13].

The most popular and effective way to organize crowdfunding is to create a website crowdfunding platform - with the ability to accept payments.

Crowdselling involves the involvement of end users in the creation and refinement of the product. ICO - a kind of pre-sale and attraction of new supporters through the initial offer coins to future holders in the form of blockchain-based cryptocurrencies and cryptoassets [14].

In addition, tokens differ in the content of the rights that the investor receives when buying them. This may be the right to receive certain assets (goods or services) or the right to participate in the management of the company. Moreover, the receipt of these benefits is possible only with the successful implementation of the project. In case of failure, return on investment is almost impossible, as this area of financial relations has no material security and is not regulated either at the national or international level.

\section{Methodology}

\subsection{Financing ICO projects: market analysis the ICO in the years 2016, 2017, 2018}

Simplified mechanism of ICO can be presented as follows. Investors investing in the company or a project based on blockchain technology, provide initiators of the placement with financial resources in exchange for tokens, which can be further used as an internal the monetary unit of the project/business (i.e. new crypto-currencies) exchanged for Fiat money and other cryptocurrencies, goods and services or to apply on exchanges in the form of digital of financial assets. As a rule, to purchase tokens, an investor will need to open a special "electronic wallet" on the appropriate technological platform, which will be used for purchase, or he must use online exchanges or exchange services in accordance with the rules established by the Issuer. In turn, the company attracting financing, using blockchain technology, carries out the issue of tokens, sets the price placement in cash equivalent and sells tokens on certain conditions for cryptocurrency or Fiat money to investors.

Technically, tokens are issued by adding transactions to the blockchain indicating their quantity, description and assigning a unique identifier. Each token placed during the ICO corresponds to an indestructible and immutable record in the blockchain, which allows it is easy to carry out its exchange and ensure safety. Once issued, tokens can be sent to any e- 
wallet in the blockchain system. Subsequently, tokens can be traded on special trading platforms or online services that allow them to be exchanged for crypto - or Fiat currencies, thus ensuring free circulation and the opportunity for everyone purchase them at market prices. The issue of tokens under the agreement with the Issuer is carried out by special blockchain platforms, among which the most popular are Ethereum, Waves, NEM, Nxt, EOS, KickICO. They differ in the features of the algorithms used, the speed of token issuance, the degree of protection, the ability to access other crypto-currency platforms and the level of commissions. Almost all ICOS are organized in the same way. The organizers publish the address of their e-wallet, where investors send money, and after the completion of the collection of funds sent to the wallets of investors tokens for a certain amount. As a result, the issuing company receives a certain amount of cryptocurrency, which can be transferred to Fiat money or used for speculation on cryptocurrency exchanges. Currently, the largest exchanges in the world are considered to be Finance (Shanghai), Bitfinex (Hong Kong), Tether, Bitrix [15].

The main form of information representation of ICO de facto is «White paper», here with any standards or regulations for training this document is missin. As a rule, White paper should contain the following sections:

- description of a business idea or problem;

- proposed solution and description of the relevant project / product;

- a description of the mechanism of implementation of the token (as interacts with product, Economics and technical implementation);

- project team;

- the parameters and terms of issue of tokens of future plans [16].

The vast majority of ICO is ICO cryptocurrency and Finance launch the respective platforms. New cryptocurrencies, as a rule, begin their existence with the release of tokens. This explains the huge variety of cryptocurrencies in world (Table 1).

Table 1. Analysis of ICOs by Category $(2016,2017,2018)$.

\begin{tabular}{|c|l|c|c|c|}
\hline \multirow{2}{*}{ № } & \multicolumn{1}{|c|}{ Category } & 2016 & 2017 & 2018 \\
\cline { 3 - 5 } & & \multicolumn{3}{c|}{$\%$} \\
\hline 1 & Infrastructure & $39.7 \%$ & $20.0 \%$ & $25.2 \%$ \\
\hline 2 & Trading \& Investing & $12.9 \%$ & $10.5 \%$ & $7.0 \%$ \\
\hline 3 & Content Management & $9.9 \%$ & $0.3 \%$ & \\
\hline 4 & Events \& Entertainment & $8.1 \%$ & $1.2 \%$ & $3.4 \%$ \\
\hline 5 & Commodities & $7.6 \%$ & $0.1 \%$ & $0.4 \%$ \\
\hline 6 & Gaming \& VR & $7.2 \%$ & $2.8 \%$ & $3.8 \%$ \\
\hline 7 & Gambling \& Betting & $5.1 \%$ & $3.0 \%$ & $1.3 \%$ \\
\hline 8 & Finance & $2.9 \%$ & $18.2 \%$ & $15.3 \%$ \\
\hline 9 & Identity \& Reputation & $2.2 \%$ & & $0.9 \%$ \\
\hline 10 & Payments & $1.8 \%$ & $7.8 \%$ & \\
\hline 11 & Social Network & $1.0 \%$ & & \\
\hline 12 & Internet of Things & $0.7 \%$ & $0.0 \%$ & $0.5 \%$ \\
\hline 13 & Transport & $0.7 \%$ & $0.3 \%$ & $0.9 \%$ \\
\hline 14 & Commerce \& Advertising & $0.3 \%$ & $1.6 \%$ & $3.2 \%$ \\
\hline 15 & Art \& Music & $0.1 \%$ & $0.8 \%$ & $0.3 \%$ \\
\hline \multicolumn{4}{|l|}{ Note: compiled by the authors based on the source www.coinschedule.com } \\
\hline
\end{tabular}

The categories shown in the table consist of the constituent members. In accordance with this detail of each category can be seen that each year decreases or increases. And some of the categories that were in 2016, you can see that in 2018 there is no. For example, if we consider the category of Social Network, we see that in 2016 the ICO project was financed and entered the market,the percentage of this project was $0.1 \%$ and in $2017-2018$ 
this category was removed from the market. In addition, the Content Management and Payments were not members of the categories in 2018.

The essence of these indicators is to determine the conditions that occur in the financing of the ICO project. That is, when new participants of each category appear, investments through the token enter the market in the future. However, all new projects appearing on the market are financed, exposed to risk and go bankrupt without entering the cryptocurrency market. As an argument, we compare investments in 2018 with total investment from 2016 year (Figure 1).

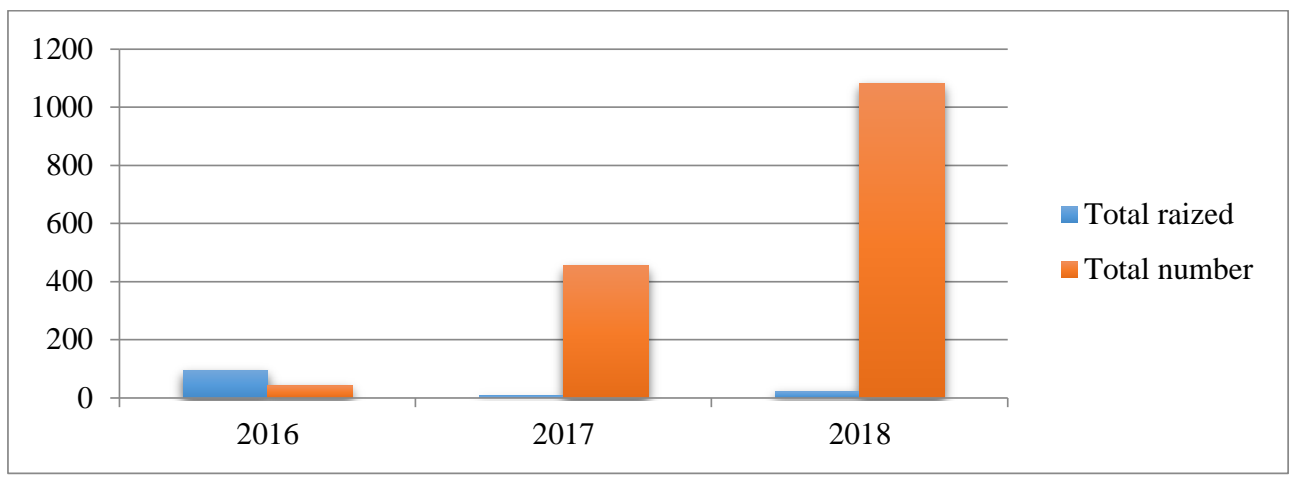

Fig. 1. Statistics of cryptocurrency ICO

According to the statistical data, in 2016 the rise, but these risks do not exclude. Because every year the number of participants increases, that is, the increase in quantity, not quality. Some of the projects which generate income, some will suffer losses.

Analyzing the statistical data of ICO projects, we noticed that it is increasing. Now let's look at the attractiveness that affects this increase, and analyze what projects are financed through ICO.

4 factors affecting the value of the cryptocurrency [17]:

(1) The opinion leaders of business areas and a ban in several countries of the world. The opinions of the leaders of the States and the relevant legislation significantly affect the situation in the crypto world. South Korean bans on cryptocurrencies at the state level only this year several times influenced the correction of the exchange rate.

(2) Oil and precious metals. Perhaps the connection between natural resources and cryptocurrencies is not immediately evident, but the pattern is as follows: if the price of oil increases, then Bitcoin goes up. Accordingly, if the price of oil falls, then Bitcoin loses its position. However, the volatility of the cryptocurrency rate is much more pronounced than the price of oil.

(3) Investment. All digital currencies, especially the little-known ones, are susceptible to the influence of investors who may intentionally or intentionally influence the price. If the amount of capital of the depositor is large enough, then you can buy a considerable percentage of a token, and then try to promote the reputation of the crypto currency to "pump" the price. Investors who observe the support of investors are more confident in the choice of cryptocurrency, and the greater the demand for the currency, the correspondingly higher its cost. By investing large amounts in a little-known token, the depositor can cause a deliberate increase in the value of the coin, and the fall of others, against this background.

(4) Information noise. The volatility of the cryptocurrency exchange rate is largely based on the hype that constantly supports interest in them. A sharp drop in the token rate can be affected both by a random post on the social network and by a deliberate statement of a well-known personality of the crypto-currency world, which is quickly spread by the 
world media. In the field of cryptocurrency news really have a significant impact on the opinion of investors and the situation in the market.

In addition, we identify global projects that are funded through ico and enter the market. We know only one fact of using ICO in the real sector of the economy, which is well covered in the media. Moscow farmer M. Shlyapnikov in April 2017 drew for your farm "Kalinovo" ICO more than 500 thousand dollars, after receiving a 401 bitcoin from 103 investors. The issue volume amounted to 1 million tokens, which are called "the colony" $(\mathrm{KLH})$ and provided real products of the farm. The idea of the ICO came to M. Shlyapnikov after an attempt to introduce a paper quasi- colion in his village in 2015, which was to facilitate the natural exchange of goods and services for local population in conditions of total lack of money. He was printed on a color printer as business cards and served a kind of promissory note. Emerged money the proportions of exchange, for example, one Colin is one goose. Already a few months later M. Shlyapnikov was brought to criminal responsibility for violation of the state monopoly on issue of funds. Only the attention of the press to the process and the wide publicity of what was happening allowed him to escape from real punishment, but the local quasi-currency was banned [18].

The ban of cash he switched the interest of M. Shlyapnikova to the blockchain and in 2016 he moved his home currency in a cashless form. Was introduced CryptoAPI and cryptorouters, offered invest in potential investors. The proposal has caused an excessive demand and cryptapi was quickly sold out. From this the shares were received about 800 thousand rubles and this put an end, as the economy could not at that time provide such growth production, which would guarantee a large investment. The money was invested in the development of production. Investors in return received regular baskets of farm products at a reasonable price with delivery to Moscow. An important source of income was the nursery, where trees are grown for urban planting and new year ate, which are sold, in including, for bitcoins.

The TON project involves the development of a new blockchain platform, worth more than $\$ 2$ billion., which will be formed in for seven years. The project is organized by Pavel Durov, the owner of Telegram, and his brother Nikolai Durov, its technical Director. Within the framework of the platform, it is planned to introduce a new cryptocurrency called Gram, which according to the developers ' plans should press bitcoin, Ethereum and other currencies. TON is formed as a multifunctional blockchain platform, which includes messenger, that is, instant messaging applications, a number of services, including fast money transfers, smart contracts, distributed storage and access to files [19].

\section{Results and Discussion}

\subsection{Prospects the use of modern technologies in Kazakhstan}

According to the rating Agency ICObench, last year 2018 ICOS were held in Russia, which allowed the country to take second place in the number of initial coin offerings. In Kazakhstan, this method of attracting investments is not so popular yet: in total, according to the website of the same Agency, only 4 ICO projects 2 of them have already been completed, 2 are in the active stage [20].

First steps into the world of ICO. Kairat Kaliyev, Deputy Director of the Department of financial technologies of the international financial center "Astana", is the first among Kazakhstanis who received experience of ICO.Kairat Kaliyev, Deputy Director of the Department of financial technologies of the international financial center "Astana", is the first among Kazakhstanis who received experience of ICO. During the professional internship in the United States, developed by AIFC together with "Bolashak", Kairat 
together with start-up accelerator Starta held an ICO. The purpose of the ICO was to attract investments in cryptocurrencies in the accelerator for the formation of a venture Fund. Of the $\$ 5$ million raised funds, $\$ 1.5$ million is used to invest in a pool of 21 startups that have already passed the acceleration program in 2016-17, the rest - in startups of future releases. In total, it is

planned to invest about 60-70 startups at the expense of attracted funds.

Today he is one of the few experts in the field of ICO in Kazakhstan. This internship is one of the first steps of the international financial center "Astana" on the way to the formation of the most favorable conditions for the development of blockchain technologies.

Mining mines are just starting the era of ICO in cryptoamnesia Kazakhstan. Startup Ice Rock Mining launches ICO mining mines and the result of this process is investments in the amount of $\$ 311$ thousand the Project is unique because is located in the former military mine. Thus, there is no need to spend money on the construction of the premises, its rent (the mine is the property of Ice Rock Mining), as well as on cooling systems for mining the average temperature in the mine is 12 degrees Celsius in the presence of natural ventilation. In addition, a great advantage is the low cost of electricity -3 cents per kilowatt. The founder of the project, Malik Murzashev, has ten years of experience in California and Kazakhstan in the field of Internet projects, software development and retail. $\mathrm{He}$ is also the founder of the largest Apple dealer in Kazakhstan. In addition, he has 5 years of experience in the implementation of blockchain projects.

Kazakhstan's cryptocurrency intends to conquer the silk road or the evolution of the cryptocurrency. Altyn coin, the Kazakhstan cryptocurrency project, started at the ICO in October. Moreover, by the architect Robert Orlando Becaria, leading engineer Vladimir Lazarev and IT expert Maksut Aushakov intend soon to bring the project to two Russian exchanges. Altyn coin is a cryptocurrency based on the 3rd generation Blockchain. This cryptocurrency was developed within the framework of the project of social network with artificial intelligence ZION.CITY.This project launched by the company "the three Alliance", which is the Union of professionals and companies of the United States, Russia, Belarus, Moldova, Ukraine, China, India and Kazakhstan. The purpose of the ICO is to attract investments in the amount of $\$ 5.5$ million Project went to the exchange Altyn tokens, that is stock, now the team is engaged in the customization project under the SCO countries, and at the end of 2018 plans to launch a project. The planned starting cost of Altyn coin is $\$ 50$. In addition, it is planned to provide this cryptocurrency with a gold reserve. From the whole list, it is to this project the least trust, as this team has in the past established itself as a team with strange and controversial projects.

Cryptocurrency forecasting, Kenes Rakishev and \$30 million. Company Invest.com Group ICO new platform forecasting cryptocurrency STOX on the Bancor. The main investor Invest.com Group acted as private venture Fund Kenges Rakishev and Moshe Hovega - Singulariteam. The company placed smart tokens of STX cryptocurrency through the Bancor Protocol to provide liquidity through the Ethereum platform. The Bancor Protocol is a built - in mechanism for determining the price and liquidity for tokens based on blockchain technology that supports smart contracts. The reserve of these smart tokens contains one or several other tokens and allows either party to instantly acquire or liquidate the smart token in exchange for one of the reserved tokens through the smart token contract. This process is carried out at a price that is constantly recalculated and according to a formula that establishes a balance between the volume of purchases and sales. The target amount of this ICO is $\$ 30$ million. However, for 34 hours, funds in the amount of $\$ 20$ million were collected, which is also a good result.

ICO-incubator. Almaty Tech Garden is preparing to launch the international program Startup Kazakhstan. According to the CEO of Almaty Tech Garden, Sanzhar Kettebekov, funding will be provided through the joint venture Fund Almaty Tech Garden and GVA 
Capital - GVA Alatau Fund. The volume of investments in startups will be up to $\$ 100000$. By 2020, about 500 innovative start-UPS will be financed and 50 high-tech export-oriented companies will be incubated. It is noteworthy that within the framework of this program, the Fund plans to help novice investors with alternative sources of financing, including the issuance of digital tokens, that is, ICO. To prepare the participants of Startup Kazakhstan, the program plans to launch an ICO-incubator. Significant support will be provided through the interaction of Almaty Tech Garden and Astana international financial center (AIFC). These two organizations and GVA signed a Memorandum of cooperation on September 20 to create an ecosystem in Almaty using blockchain technology . In addition, The center for technological development of intelligent technologies, including intelligent systems in cooperation with IBM, will be launched.

The Soy-Coin project combines technologies in the field of Finance and industrial complexes for processing soybeans. The main objective of the project SoyCoin is the creation of the largest international efficient agriculture, which will deal with the processing and sale of soy beans, waste-free and environmentally friendly product.

The Pre-ICO project, organized on the basis of the Ethereum platform, has already started and will be completed in 24 days. The fundraising during the ICO will be divided into 2 pools: the 1st pool is designed for the construction of a plant in Kazakhstan, the 2nd pool is designed for the construction of plants in China and Japan. The minimum amount for the launch of the first line of the plant is $\$ 5$ million. Investments in the company will be made by purchasing the SYC token, which is the fuel of Soy-Coin.After the end of the fundraising, a "Swiss parent company" will be established, which will be the owner of all assets and distribute profits among investors.he founder of the project - asset Bakashev, has 17 years of experience in business and is the Director of the company "Assar Group", which is responsible for all the processes of the project before the creation of the"Swiss company". According to the roadmap of the project, the investment campaign is planned for the period from November 2017 to March 2018. This is followed by the purchase, production of equipment and start of production by March 2019. And in June of the same year it is planned to buy SYC tokens from investors.

In our opinion, the ICO picture in Kazakhstan looks quite promising and promising. And this is good, because this phenomenon really deserves a place in the emerging cryptoeconomy of Kazakhstan. We hope that there will be more such projects in the foreseeable future, and most importantly, let all of them meet the expectations of their investors.

There is no regulation, but there are first steps in this direction. For example, at the end of last year, Kazakhstan created the "Kazakhstan blockchain Association". At the beginning of the year, ESET Butin, Chairman of the Association Council, said that within the framework of the Association it is planned to create an expert Council: "we will conduct an examination of such projects arising in Kazakhstan, and recommend people to invest in them or not after a thorough study of the projects." At the conference in Almaty, ESET Butin will touch upon the regulation of the cryptocurrency industry in the Republic of Kazakhstan and the Customs Union. Global trends in ICO projects will not bypass Kazakhstan. According to the ICO Rating Agency, in the first half of 2017, successful ICO was $50 \%$ or more, in the summer - a third, in the autumn — less than $20 \%$. This suggests that the market is becoming more Mature: teams are more professional, investors are smarter. More stringent requirements for ICO projects, tougher regulation by government agencies, as well as the arrival of institutional and venture investors in the ICO market these changes are waiting for the ICO market according to Mikhail Sergeyev.

"There is less and less room for imagination in the industry, and more and more opportunities for projects that have solid ground under their feet and realistic plans for the future, supported by the already existing results, the competence of the team and strong financial support. More and more projects on the market are not startups, but existing 
previously and scalable through ICO, which is an absolute plus for investors both in terms of the guarantee of profit and the fact that the project will not be a Scam", — sums up Evgeny Shchelkonogov, International Auto Club.

\subsection{ICO advantages}

After studying the project, which began with ICO, we noticed that ICO is suitable for financing new startups. The emergence of a new market and its rapid development, the lack of full regulation, a large number of investors wishing to make money in the market, as well as other factors contribute to increasing interest in studying the possibilities of the ICO market. So, consider the possibilities ICO market to attract investment in start-up projects:

1. A large amount of financial resources.

2. There is a large number of investors in the market: as private investors individuals and investment funds. That is why start-up projects open up opportunities to attract investment in the required amount.

3. Openness of the market to start-up entrepreneurs.

4. Freedom and lack of special regulation of the ICO procedure. In the conditions of high uncertainty in the ICO market, there is a great freedom of action and there are no generally accepted standards for ICO. The attitude of regulators of the world to the market is mostly positive or neutral. Only 2 countries at the beginning of 2018 took steps to ban ICO-China and South Korea. To a greater extent, the ICO supports the Isle of man, Switzerland and Singapore [21].

5. The minimum cost of attracting investment. Due to the relative simplicity of the ICO procedure, start-up projects can reduce costs, and there is no need to prepare standardized documents (usually such documents needed in preparation for the IPO), make this procedure even more budgetary.

6. No need to give a stake in the company to investors. During the ICO and token sale, the investor receives only a conditional unit of exchange, and not a share in the company, as is the case with an IPO or venture investment. This makes it possible the founders of the project to make adjustments to the project and determine its future direction (Electronic resource) (Table 2).

Table 2. ICO advantages.

\begin{tabular}{|c|c|}
\hline Advantages for entrepreneurs-ICO founders & ICO advantages for investors \\
\hline $\begin{array}{l}\text { - Effective fundraising; } \\
\text { - ICO is much cheaper than IPO; } \\
\text { - The launch of the ICO is associated with much } \\
\text { less paperwork than the IPO; } \\
\text { - Opportunity to tell the General public about } \\
\text { your brand and cryptocurrency; } \\
\text { - Building a community; } \\
\text { - The opportunity to acquire early investors and } \\
\text { use them as a marketing mechanism to promote } \\
\text { the project; } \\
\text { - Entrepreneurs share with investors all the risks } \\
\text { and rewards; } \\
\text { - Founders / developers are given the } \\
\text { opportunity to attract funding to the project, } \\
\text { which will allow them to apply their skills in } \\
\text { the best way; } \\
\text { - Dear specialists of the cryptocurrency market } \\
\text { have the opportunity to earn using their }\end{array}$ & $\begin{array}{l}\text { - various transparency mechanisms, such as } \\
\text { escrow, can be used to control the } \\
\text { expenditure of funds after the ICO; } \\
\text { - early investors will have better liquidity } \\
\text { early; } \\
\text { - early access to the token, which has the } \\
\text { potential for price growth; } \\
\text { - there is no regulation or registration by } \\
\text { government authorities, and investor } \\
\text { protection is provided only by means built } \\
\text { into the platform itself; } \\
\text { - investors can be part of the community; } \\
\text { - an innovative way of allocating capital; } \\
\text { - ICO, using existing networks such as } \\
\text { Stratis, Ardor and Ethereum, gain access to } \\
\text { the network capital of the existing } \\
\text { ecosystem; } \\
\text { - transfer of investments from the main }\end{array}$ \\
\hline
\end{tabular}


knowledge and reputation acquired over the years;

- Proof-of-stake cryptocurrencies with ICO solve the problem of fair distribution;

- Venture capital financing involves the intervention of an investor in the activities of the founder;

- An alternative to ICO can serve as a loan of funds, which imposes many restrictions on the cash flows of the project, which is not always acceptable in the case of working with cryptocurrencies. cryptocurrencies to alternative ones; - investors, as a rule, are also the first users of alternative currencies - in contrast to shares, where investors may not use the company's products at all. In this sense, ironically, cryptocurrencies are more tangible than other investments;

- investment in ICO can bring a return of several thousand percent;

- diversification into other assets;

an investment with high returns and high risks, which to some extent is not related to the stock market and the economy;

ownership of an alternative asset not linked to a traditional currency.

On ICO, you can both earn and lose money. This is one of the most risky types of investment. A potential investor can conduct a comprehensive examination of the project, but the success of the ICO will depend on a number of factors beyond the control of the project creators. There is a high probability that the ICO will go wrong, as expected.

\subsection{Risks in ICO and their management}

ICO risks should be considered from two sides: investors and creators. In a global sense, all risks can be divided into external and internal. External ones are the regulation of the ICO process, and internal ones are directly related to the project itself. It should be noted that today the biggest risks that both parties bear - legal (external). This is due to the fact that this process is not regulated at the state level.

There are many internal risks for potential investors in the ICO market:

- one of them is the risk of fraud. In his article, argues that the risk of fraud is due to the fact that at the moment the ICO is in the gray zone of world law, the creators of the projects do not have any obligations to investors. They convinced potential investors of the need for the product, raise money and dissolve [22];

- the risk of terrorism as another form of fraud. Investments in financial schemes that use digital tokens, due to the anonymity of transactions and the flexibility to attract significant amounts in a short period of time, are attractive to persons involved in illegal activity;

- risk of hacker attack on the project. This would include the situation presented by Ruslan Alekperov, Director of the private client Group-IB: "There are also cases when a hacked admin account of the community project in the Telegram and on his behalf by the false announcement of redirecting the audience into an alternative platform for tocansale. So criminals "took away" hundreds of thousands at the minimum cost of operation";

- risk of investing in a failed project, business model. This is influenced by many factors. According to analysts, this may be due to the selection of an unprofessional team [23].It is necessary to pay attention to the past project experience of each of the participants, their understanding of the legal, economic, business component on the part of the creators of the project;

- the risks of project creators are closely intertwined with the risks of investors. Due to the fact that the preparation and the ICO itself is a long process, there is a risk that a competing project will be launched on the market earlier;

- risk of illiterate preparation of the business plan and related documentation. For greater clarity and transparency of the project creators need to clearly describe the scheme 
of investor protection, make a business plan, prescribe the value of the project for investors. "The lack of a business plan, the calculation of cash flow should alert a potential buyer of tokens. This is, at least, a signal to the fact that a clear concept of the project and mastering the received the organizers of this ICO do not have funds", says Ekaterina Malyarova, candidate of legal Sciences [24];

- financial losses. One of the distinctive features of the ICO project is the type of attracted money (both traditional money and crypto-currencies can be attracted). In the case of attracting cryptocurrencies, there are risks associated with insufficient liquidity in the secondary market, which threatens to lose part of the funds when they are converted into a traditional currency, for example, due to the high commissions.

Thus, we have made work on generalization and structuring risks for investors and project developers, presents a classification of risks on internal and external. In order to minimize and manage the risks presented above and reduce the number of unsuccessful projects, in our opinion it is necessary:

- to develop legal documents that will regulate the procedure of ICO and the rights and obligations of its participants at the legislative level. This will allow, first of all, to avoid unfair and irresponsible behavior of ICO participants, as well as prevent the appearance of imaginary projects on the market;

- to increase the General literacy of the population regarding the world of blockchain technologies and cryptocurrencies, as the second place among the risks allocated by us is the illiteracy of investors and an unprocessed approach to the ICO of project creators. As far as investors are concerned, there is a need to disseminate more accessible information regarding procedures for selection and evaluation of investment directions. As for the creators of the projects, there is only one way to solve this - fixing the responsibility of the parties at the legislative level in case of failure.

Summing up all the above, we note that the ICO market is only an emerging market, which is not without its advantages and disadvantages, but we must not forget that everything the new needs freedom for development and self-realization, therefore, by establishing legislative barriers, it is necessary to leave the ways and opportunities for the economy to move forward $[25,26,27]$.

\section{Conclusion}

During the study, it was found out that ICO or initial placement of coins (tokens) is a way to attract primary capital with the help of cryptocurrencies, by analogy with IPO (Initial Public Offering - initial placement of shares of the company), which is not available to most startups, because it is necessary to earn a certain reputation during some years. The main condition of the ICO is the acquisition by the company of obligations to token holders, which can be expressed in the form of payment of dividends of a significant amount-up to $30 \%$ per annum, discounts for the provision of services, tokens can be redeemed at a higher price than at the time primary placement, as well as investors can take part in voting in the management of the company (the number of votes is equal to the number of tokens) and earn on the growth of the chosen cryptocurrency, which is several times higher than the liquidity of tokens.

In order to visualize the opportunities and threats arising from the ICO application, we have presented a SWOT analysis of the ICO (Table 3).

Table 3. SWOT analysis ICO.

\begin{tabular}{|c|c|}
\hline Strength & Weakness \\
\hline
\end{tabular}




\begin{tabular}{|c|c|}
\hline 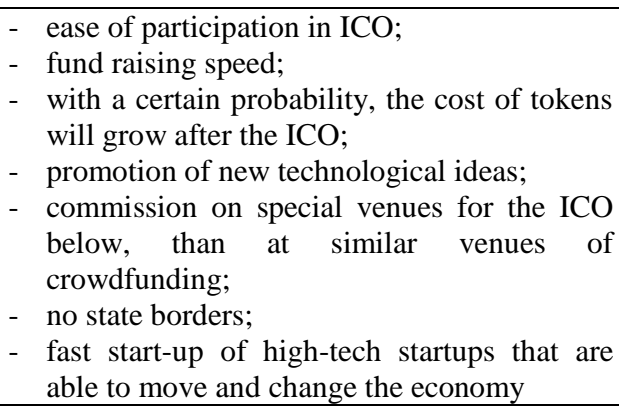 & $\begin{array}{l}\text { - lack of legislative regulation; } \\
\text { - after the collection of funds, the project may } \\
\text { cease to exist; } \\
\text { - a large number of false ICO and projects } \\
\text { with a low level of trust }\end{array}$ \\
\hline Scope & Threats \\
\hline $\begin{array}{l}\text { - possibility for each interested person to take } \\
\text { part in any project; } \\
\text { - the ability to raise funds regardless of the } \\
\text { location and jurisdiction of the investor }\end{array}$ & $\begin{array}{l}\text { - fraud; } \\
\text { - loss of funds; } \\
\text { - the drop in the cost of tokens; } \\
\text { - excessive regulation by the state; } \\
\text { - mistrust on the part of society }\end{array}$ \\
\hline
\end{tabular}

The strength is the ease of participation. Indeed, thanks to the "smart contracts" on which the ICO works, it is enough for a person to simply transfer funds from his cryptowallet to the crypto-wallet of the project. Literally after that, a certain amount of tokens will come to the participant's wallet, and participation takes no more than 20 minutes. If the project will be able to interest large masses of people, the required amount is collected quickly enough. This is ensured by the fact that anyone can participate in the ICO, if it is not prohibited by the legislation of his country. In this case, the funds are collected not so much at the expense of the size of contributions, but at the expense of the number of participants. Thanks to the development of high-tech projects, ICO contributes to the development of the entire world economy. A special role is played by globalization, which develops due to the lack of state borders during the ICO.

The main weakness is the lack of legislative regulation, which significantly increases the number of fraudulent transactions in this area. However, excessive legislative regulation can stop the development of the ICO market. There will be the same situation that is happening now in the securities market. The ban on participation in the initial placement of securities for citizens, the introduction of any barriers equates ICO to IPO, which will make further development impractical.

Thus, it is worth noting that the ICO market is only in the stage of development, but thanks to its novelty and the opportunities that the initial placement of coins provides, the ICO spreads quickly enough.

Despite certain advantages of ICO, its use to Finance even technology companies and projects is associated with a number of problems. Usually the first place put forward the problem of a legal nature, some of which were discussed above. However, in addition to the legal insecurity of investors, which sooner or later will be solved, there is another problemthe assessment of the efficiency of investments, and subsequently-the prospects for the growth of the value of tokens during the operations on the stock exchanges. In the case of the use of borrowed tools there is a problem of assessing the creditworthiness of the enterprise, which may exist only in the form of an Internet page, does not have real assets, and therefore proper security. At the same time, the main economic reason for the existence of both problems is that many ICO projects are startups or poorly monetized because of their features. They are not able to generate cash flows, that significantly hampers their financial assessment of existing methods. At first glance, ICO by companies of the real sector of the economy is free from these problems. However, in this case there are other 
problems, such as the volume of attracted funding, the organization of further circulation of tokens, their conversion and implementation related rights.

In order to reduce these risks, it is necessary to ensure the regulation of ICO activities, which will contribute to the development of the economy. Of course, it is not possible to consider all possible risks in the ICO market within one article, which is why the most frequent and actual risks that almost any ICO project can face were considered. Thus, the ICO market provides great opportunities to attract investment in start-up projects. However, if you do not take into account the risks that may stand before entering the ICO, then the probability of successful attraction of investments becomes much lower. It is worth noting that the ICO market in the near future may become one of the main alternatives to other conventional methods of attracting funding for start-up projects.

Summing up all the above, we note that the ICO market is only an emerging market, which is not deprived of its advantages and disadvantages, but we must not forget that everything new needs freedom for development and self - realization, therefore, by establishing legislative barriers, it is necessary to leave the ways and opportunities for the economy to move forward.

\section{References}

1. I. Ya. Lukasevich, ICO as a Business Financing Tool: Myths and Reality (Moscow, 2018)

2. A.J. Chapin., Art of the Initial Coin Offering: Lessons Learned from the Launch of a Crypto-Token, 120 (Bowker, New York, 2017)

3. R. Pukala, N. Vnukova, S. Achkasova, V. Smoliak, Economic Annals-XXI, 5 (6), 152-156 (2017)

4. S. Ziyadin, R. Doszhan, A. Borodin, A. Omarova, \& A. Ilyas, E3S Web of Conferences, 135, 04022 (2019) DOI: 10.1051/e3sconf/201913504022

5. S. Ziyadin, R. Doszhan, G. Saparova, A. Omarova, Proceedings of the 32nd International Business Information Management Association Conference, IBIMA 2018 - Vision 2020: Sustainable Economic Development and Application of Innovation Management from Regional expansion to Global Growth, 3379-3383 (2018)

6. S. Ziyadin, B. Ermekbaeva, G. Supugaliyeva, R. Doszhan, Proceedings of the 31st International Business Information Management Association Conference, IBIMA 2018: Innovation Management and Education Excellence through Vision 2020, 20092017 (2018)

7. S. Ziyadin, A. Omarova, R. Doszhan, G. Saparova, \& G. Zharaskyzy, Problems and perspectives in management, 16(4), 331-343 (2018). DOI: 10.21511/ppm.16(4).2018.27

8. K. Mukhtarova, S. Ziyadin, S. Kupeshova, \& R. Doszhan, Economic annals-XXI, 168, 38-43 (2017). DOI: 10.21003/ea.V168-08

9. U. W. Chohan, Vanderbilt University Department of Economics Working Paper Series, 17- 00008, 1-18 (2017)

10. J. P. Conley, Vanderbilt University Department of economics working papers, 1700008, 1-20 (2017)

11. K. Bely, What is a token? (2018)

12. M. N. Pervyshin, D. A. Kornilov, D. Zaytsev, Eonomics and entrepreneurship, 5-1(461), 662-665 (2014)

13. D. N. Sedov, D. A. Kornilov, Innov: electronic scientific journal, 4 (29) (2016)

14. D. A. Kornilov, D. A. Zaitsev, E. V. Kornilov, IT portal, 3 (15) (2017) 
15. T. A. Fedorova, ICO and problems of economic security (2018)

16. I. Ya. Lukasevich, (2018) ICO as a Business Financing Tool: Myths and Reality (Moscow, 2018)

17. L. Leonova, 4 factors affecting the value of cryptocurrency (2018)

18. T. Bikbulatov, Sober and we think, how to develop after ICO. As a Moscow banker anarchist fled to the village and came up with his own cryptocurrency. Report By Taisiya Bikbulatova (Meduza Project, 2017)

19. A. Baulin, I. Mokrousov, Tectonic platform. Forbes recognized Pavel Durov dollar billionaire (2017)

20. Electronic resource "Kaspersky Lab" sums up the 2017 https://www.kaspersky.ru/

21. A. Shcherbin, ISO Producer Where to conduct ICO: the best countries (2018)

22. A. Knyazev, Investments via bitcoin: what is a ICO and should I use it? (2017)

23. Electronic resource ICO: main risks https://bitnovosti.com/

24. Klimov M., ICO Risks: how not to lose money and keep freedom in the pursuit of capital (2017)

25. Ko, H., \& Min, K. Economics \& Sociology, 12(2), 253-264. (2019).

26. Oliinyk, V., \& Kozmenko, S. Forecasting and management of gross domestic product. (2019).

27. Akhmedov, E. Journal of International Studies, 12(4). (2019). 